\title{
Fertility and partnership status in the last two decades
}

Louise O’Leary, Eva Natamba, Julie Jefferies, Ben Wilson

Office for National Statistics

\section{Abstract}

The family context in which babies are born is of continuing interest to policy makers. This article begins by reviewing trends in births within and outside marriage in England and Wales in the last two decades. It then examines the driving factors behind the ongoing rise in the proportion of births outside marriage, with particular focus on the proportion of married women of childbearing age, and changes in marital and non-marital fertility rates.

Given the variety of modern living arrangements into which children are born, the emphasis of the article then shifts to non-marital births within cohabiting partnerships. For the first time estimates of fertility for cohabiting women of different ages are presented. These are based on information collected at birth registration and survey estimates of the cohabiting population. Fertility rates for cohabiting women are then compared with those of married women and other (non-married, non-cohabiting) women.

Although there are limitations to the methodology, the article shows that over the past two decades, cohabiting women in England and Wales have had an overall level of fertility below that of married women but considerably above that of other unmarried women. 


\section{Contents}

Abstract

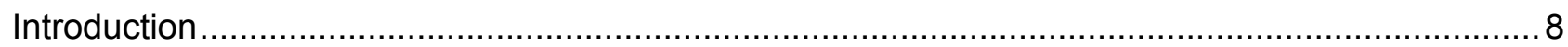

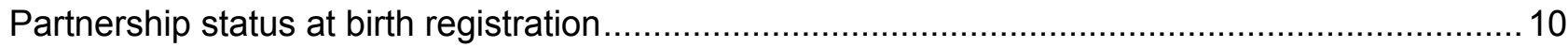

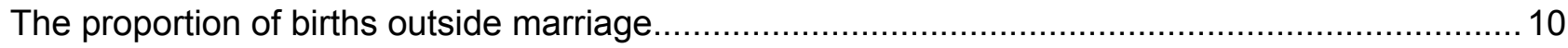

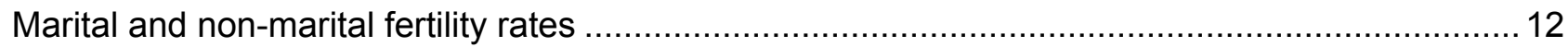

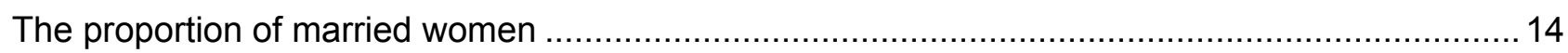

What has driven recent increases in the proportion of births outside marriage? ........................ 16

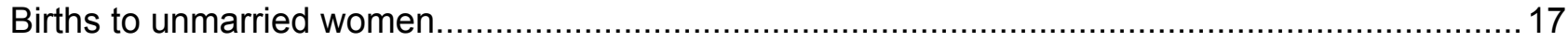

Estimating the female population by partnership status ........................................................ 19

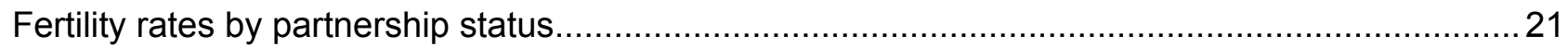

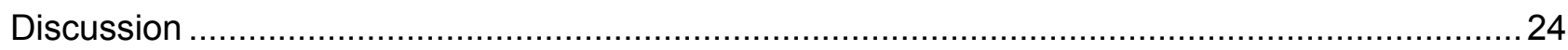

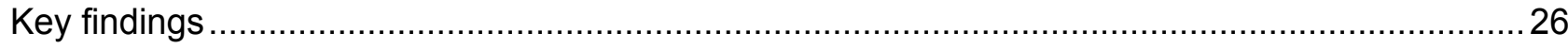

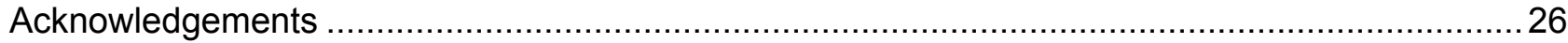

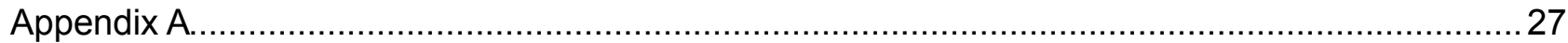

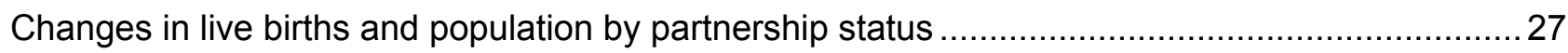

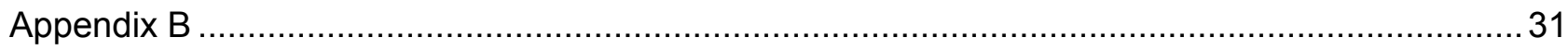

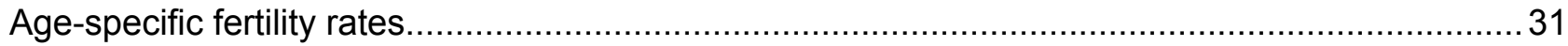

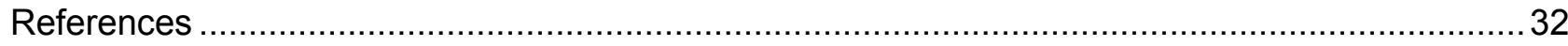

\section{List of figures}

Figure $1 \quad$ Total Fertility Rate (TFR), England and Wales, 1991-2008 …............................ 9

Figure 2 Percentage of births outside marriage, England and Wales, 1971-2008 ............... 11

Figure 3 Percentage of births to women in each age group occurring outside marriage, England and Wales, selected years

Figure 4 TFR, Marital TFR and Non-marital TFR (indexed), England and Wales, 1991-2008 
Figure 5 Marital and non-marital age-specific fertility rates by age group, England and Wales, selected years

Figure 6 Percentage of women aged 16-44 who are married and not married, England and Wales, selected years

Figure 7 Percentage of women married by age group, England and Wales, selected years

Figure 8 Percentage of live births to married, cohabiting and other/lone women, England and Wales, selected years

Figure 9 Percentage of births to mothers in a cohabiting relationship by age group of mother, England and Wales, selected years

Figure 10 Percentage of women aged $16-44$ by marital status, England and Wales, selected years

Figure 11 Estimated total fertility rates by partnership status and by quinary age groups, indexed rates, England and Wales, selected years.

Figure 12 Fertility rates by partnership status and age group, England and Wales, selected years

\section{List of tables}

Table A1 Number of live births in 1991, 2001 and 2008 by partnership status, England and Wales.

Table A2 Changes in the number of live births between 1991 and 2001 by partnership status, England and Wales

Table A3 Changes in the number of live births between 2001 and 2008 by partnership status, England and Wales

Table A4 Female population aged 16-44 in 1992, 2001 and 2007 by partnership status, England and Wales

Table A5 Changes in the female population aged 16-44 between 1992 and 2001 by partnership status, England and Wales....

Table A6 Changes in the female population aged 16-44 between 2001 and 2007 by partnership status, England and Wales.

Table B1 Estimated fertility rates by partnership status, age group and year, England and Wales. 


\section{Introduction}

Over the last two decades there has been a variety of changes in childbearing and partnership behaviour among women living in England and Wales. In terms of partnerships, the proportion of women of childbearing age who are married has fallen from 53 per cent in 1991 to 34 per cent in $2008^{1}$. During the same period, the mean age at first marriage for women has risen from 25.5 years in 1991 to 29.9 years in $2008^{2}$. These changes in marriage behaviour have been accompanied by increases in the proportion of women cohabiting ${ }^{3}$, and the proportion living alone ${ }^{4}$.

With regard to childbearing, the Total Fertility Rate (TFR) (see Box one) in England and Wales fell during the 1990s, from 1.82 in 1991 to its lowest recorded level of 1.63 in 2001 (Figure 1) ( $^{5}$ However, during the first decade of the 21 st century there has been a sustained increase in fertility, with the TFR reaching 1.97 in 2008, its highest level since the early $1970 \mathrm{~s}^{6}$. Women's mean age at childbirth has risen consistently during both decades, increasing from 27.7 years in 1991 to 29.3 years by $2008^{7}$. This is partly a result of the almost uninterrupted increases in the fertility of women in their thirties and forties that have been taking place since the early 1980s. During the 1980s and 1990s, the highest fertility rates were seen among women aged $25-29^{8}$, but in 2004 fertility rates for women aged 30-34 overtook those of the younger group for the first time.

Changing age patterns of fertility are linked to social, cultural and economic factors and have occurred simultaneously with changes in partnership formation. Changes in the number of births to women in different types of partnership provide contextual information about fluctuations in period

\section{Box one Total Fertility Rate}

The Total Fertility Rate (TFR) is the average number of children a hypothetical woman would have if she experienced the age-specific fertility rates calculated for a particular year throughout her childbearing years. It is used here as an overall period measure of fertility that can be compared over time. In 2008 the TFR in England and Wales was 1.97, which means that based on the age specific fertility rates of that year, an average woman would have 1.97 children during her lifetime.

The TFR is calculated from the sum of Age-Specific Fertility Rates (ASFRs). These are the number of live births in a year occurring to mothers in each age group, divided by the number of women of that age in the population at mid-year (presented as live births per 1,000 women in each age group).

The TFR provides an age-standardised indicator for looking at changes in period fertility over time and is effective for comparing the fertility of groups of differing size and age distributions. However care should be exercised in interpreting trends over time in the period TFR presented here. While the TFR is widely used as a summary measure of a population's current and historic fertility trends, it reflects changes in the timing (tempo) as well as level (quantum) of fertility.

Tempo effects result from cohorts of women delaying having children only to catch up in subsequent years (or conversely having children at earlier ages rather than later). This can make period fertility unrepresentative of the total number of children women may have over their lifetime ${ }^{9}$. 


\section{Figure 1 Total Fertility Rate (TFR), England and Wales, 1991-2008}

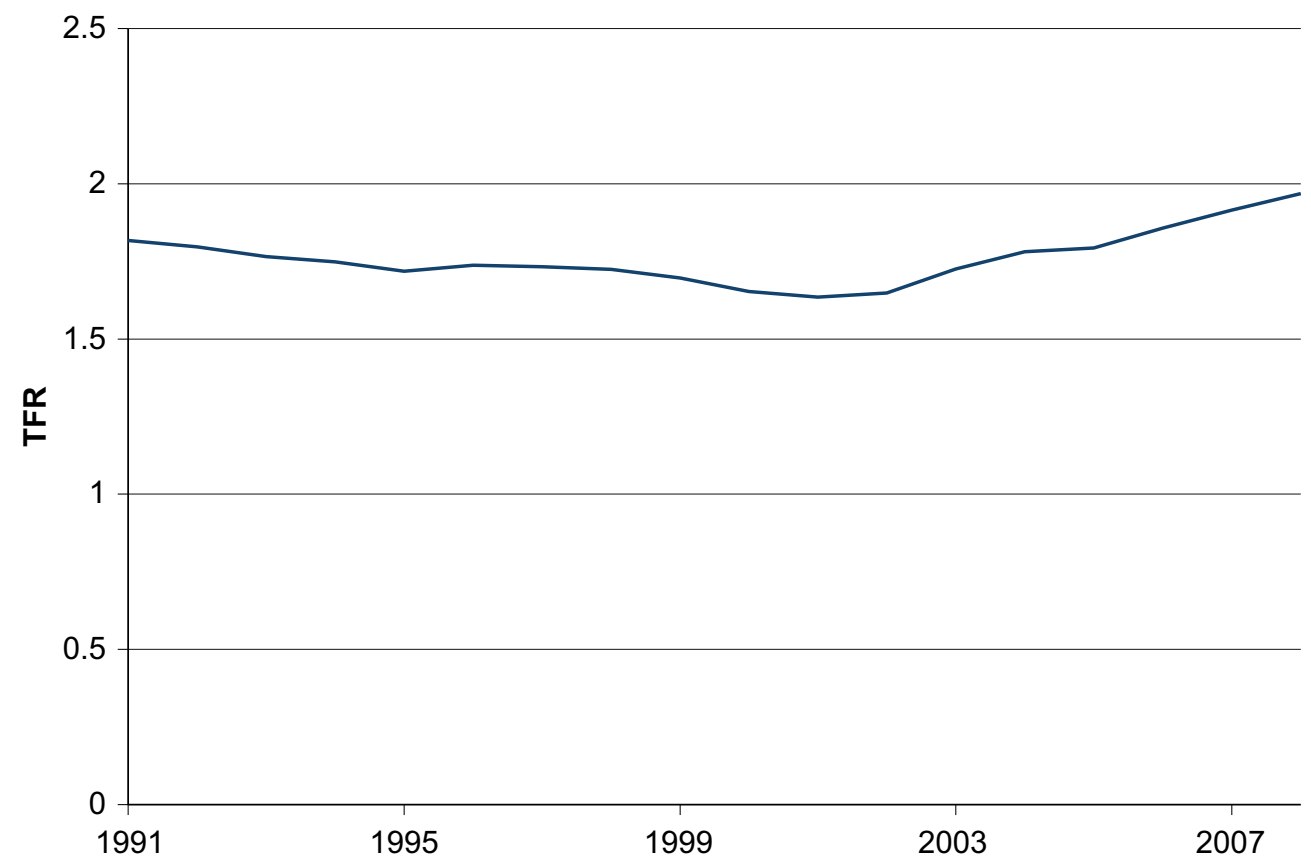

Source: Table 1.4 FM1 Birth statistics

fertility rates over the last two decades. This article therefore draws together changes in both childbearing and partnership trends and aims to enhance existing knowledge of the underlying reasons behind the recent rises in the TFR. The findings will then be used more widely to inform the fertility assumptions underpinning the ONS National Population Projections.

To begin with, the article examines a 'traditional' indicator of change for both fertility and partnerships: the proportion of births taking place outside marriage. It explores the relative contributions of changes in fertility and changes in marriage as drivers of the increasing proportion of births outside marriage during the 1990s and since the turn of the century.

Recognising that births outside marriage are increasingly taking place within cohabiting unions, the second part of the article examines the links between cohabitation and childbearing. It seeks to address the following questions:

- What has been the contribution of births within cohabitation to overall changes in the number of births since 1991?

- How has the partnership status of women of childbearing age changed since 1991?

- How do fertility rates for cohabiting women compare with those for married women (and those for women who are neither married nor cohabiting)?

To answer the final question, period fertility rates for cohabiting women in England and Wales have been estimated for the first time, for selected years. Marital status estimates and cohabitation estimates underpinning the marital, non-marital and cohabiting fertility estimates presented in this article are not available at a subnational level. Therefore the geographical scope of this article remains at the England and Wales level throughout. 


\section{Partnership status at birth registration}

For this article, parents' partnership status at birth has been inferred using the information from birth registration. On registering a birth, the parent is asked: "Are you married to the child's mother/ father?" If the answer is "yes" then the birth is registered as "within marriage". Therefore whether a birth is registered as within marriage is defined by the declared relationship of the child's parents at the point of registering the birth, rather than by the legal marital status of the mother. Births can also be registered within marriage when the child was conceived to married parents, even if they later separate/divorce or the father dies before the birth.

Births may be registered outside marriage in one of two ways:

1. As a sole registration, where the mother registers the birth alone and no information on the father is reported.

2. As a joint registration, where the mother and father are not married to each other, but are both present to register the birth ${ }^{10}$.

Birth registration is underpinned by legislation, and the data collected are considered to be of high quality ${ }^{11}$. It is assumed that the information provided by the informant is correct, however, in some cases the type of registration may not match the actual parental partnership status. For example, Smallwood (2004) found (using data from the Millennium Cohort Study), that an estimated one in twelve sole registered births in the United Kingdom actually took place within a cohabiting relationship ${ }^{12}$.

\section{The proportion of births outside marriage}

Historically, babies outside marriage were labelled as illegitimate, although not all were without a father present. A proportion of these babies will have been born within a common-law union. Similarly today, the lack of a marriage certificate does not necessarily imply that the father is not involved with the child or that he is not living with the mother. That said, birth registration data alone can only provide information to infer the partnership status of a child's parents at the time of birth, and cannot tell us anything about the family situations in which children grow up.

Statistics show that the proportion of births outside marriage was stable for much of the 20th century. The proportion of births outside marriage remained around four to five per cent until the 1960s when it began to rise, reaching 13 per cent in $1981^{13}$. The steepest increase in the proportion of non-marital births was observed during the 1980s (Figure 2), so that by 1991, 30 per cent of births took place outside marriage. By 2001, the figure had reached 40 per cent and by 2008 , although the majority of births were still occurring within marriage, 45 per cent of babies were born to unmarried parents.

Figure 3 shows the percentage of births outside marriage by age group for the years 1991, 2001 and 2008. It demonstrates that increases in the proportion of non-marital births since 1991 has occurred across all age groups.

The age pattern of non-marital births has remained fairly stable. In each of the three years, the share of births outside marriage is highest for women in the youngest age groups and lowest among women aged 30-34. For example, 94 per cent of births to women aged under 20 occurred outside marriage in 2008 (although births to women under 20 represented only 6 per cent of overall births), but the proportion outside marriage for women aged 30-34 was only 28 per cent. 
Figure 2 Percentage of births outside marriage, England and Wales, 1971-2008

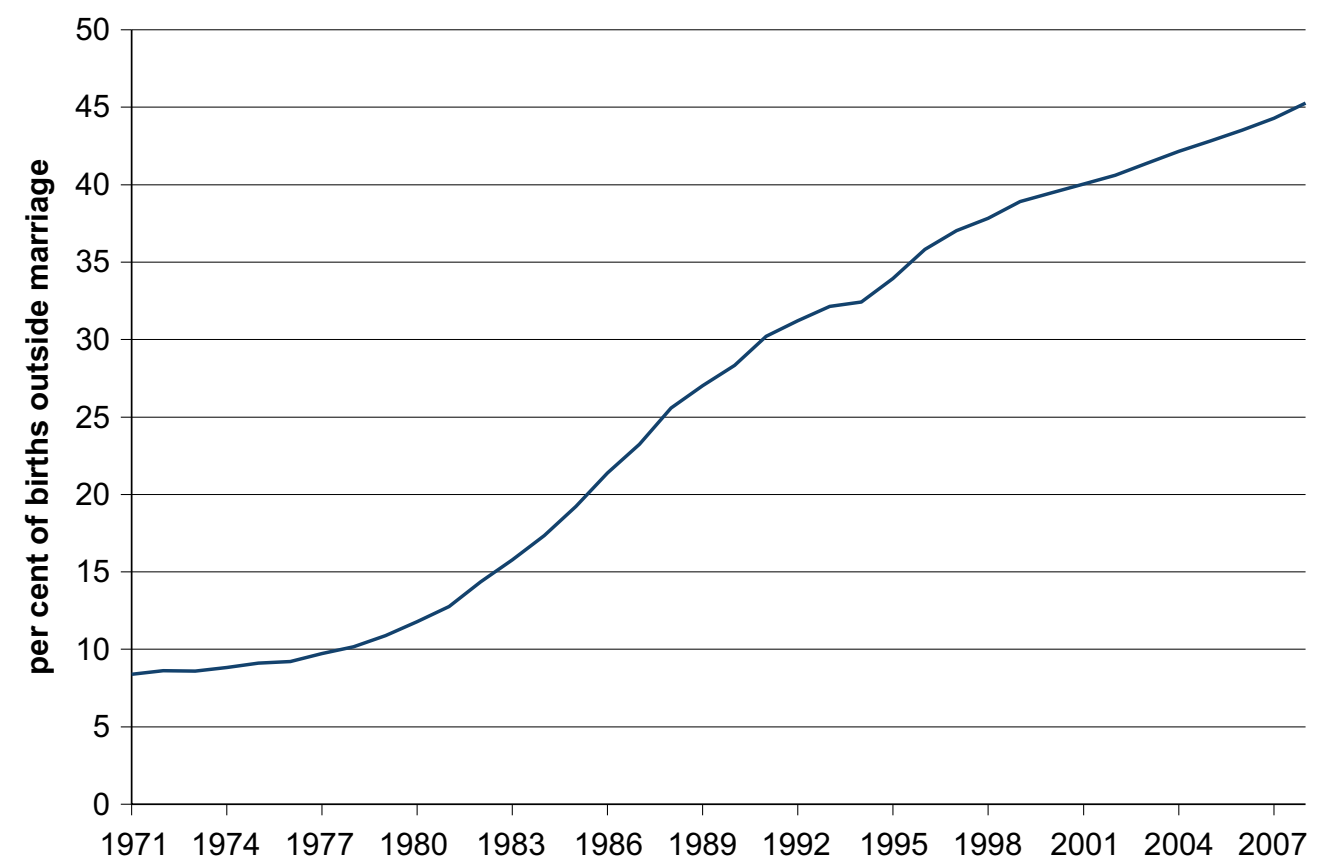

Source: Table 1.1 Birth statistics, FM1 series, and Historical series 1837-1983, HMSO

Figure 3 Percentage of births to women in each age group occurring outside marriage, England and Wales, selected years

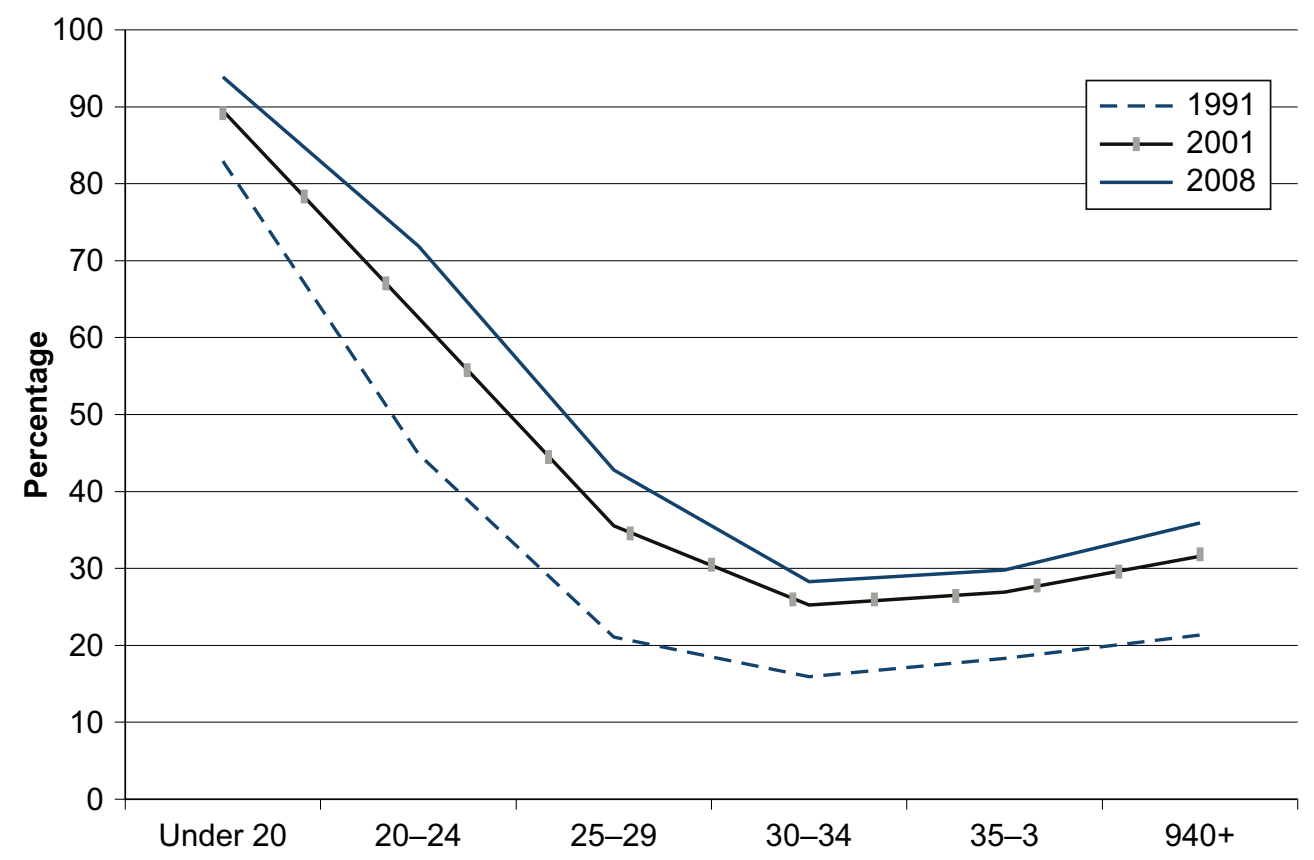

Source: Table 3.1 Birth statistics FM1 series

Compared with women aged 30-34, the proportion of non-marital births is slightly higher among older women (36 per cent among women aged 40 and over). This underlines the fact that childbearing outside marriage is by no means restricted to the youngest groups of women. In terms of numbers, there were more births outside marriage to women aged 35 and over in 2008 than to women under 20. 
To explain the above trends, it is important to understand the main drivers of the proportion of births outside marriage. Broadly, the drivers are: (a) fertility rates, of both married and unmarried women; and (b) the proportion of women that are married. These are explored in turn below.

\section{Marital and non-marital fertility rates}

A description of the Total Fertility Rate and Age-Specific Fertility Rates are given in Box one. It is possible to calculate similar indicators to measure overall marital and non-marital fertility using population estimates by marital status as denominators ${ }^{14}$.

The two indicators described below are theoretical concepts, used here to provide a quantified basis for comparison; however they should be interpreted with caution.

The Total Marital Fertility Rate (TMFR) is the number of children a woman would have by the end of her childbearing years, assuming she married on her 16th birthday and remained married for the duration of her childbearing years (up to her 45th birthday). In practice few women will experience this specific marital trajectory, but the TMFR is a hypothetical measure that allows comparison of fertility within marriage with fertility outside marriage. The TMFR also incorporates the fertility of remarried women as well as women married only once. The measure assumes those women who divorce or are widowed will remarry immediately and therefore cannot represent the lifetime experience of a real woman.

The Total Non Marital Fertility Rate (TNMFR) represents the fertility of unmarried women. Again, it is a hypothetical measure of the number of children a woman would have by the end of her childbearing years, assuming she remained unmarried between her 16th and 45th birthdays. In fact, this measure incorporates the fertility rates of widowed or divorced women, as well as those who never marry, so again cannot represent the lifetime experience of a real woman. Nevertheless, the TNMFR is provided to give a comparison to the TMFR.

Figure 1 showed the overall TFR for the period 1991 to 2008 . In Figure 4 the overall TFR is presented as an index set at 100 in 1991. Figure 4 also shows the total marital and non-marital fertility rates indexed with reference to the overall TFR in 1991.

The marital TFR (TMFR) appears very high relative to the TFR, but this can be attributed to the very high marital fertility rates at young ages which tend to skew marital fertility estimates. In 1991 the TMFR was over twice as high as the TFR and the gap between the TFR and TMFR continued to extend after 2001, so by 2008 the TMFR was over three times as high. This does not imply that the average married woman has three times as many children; a woman first marrying around the average age of 30 would only be at risk of a marital birth for half of her childbearing lifetime and then would be exposed to lower marital fertility rates at older ages. Even assuming that this woman remains married, her marital fertility is likely to be considerably lower than the relative size of the TMFR would imply.

One advantage of Figure 4 is that it identifies two separate periods of interest: (a) fertility decline from 1991 to 2001 and (b) rising fertility from 2002 to 2008. In the context of marital and nonmarital fertility, this time period also offers two distinct trends. During the 1990s, both the TMFR and the TNMFR (non-marital TFR) were relatively stable, albeit at very different levels, with total fertility among married women around four times higher than for unmarried women. 


\section{Figure 4 TFR, Marital TFR and Non-marital TFR (indexed), England} and Wales, 1991-2008

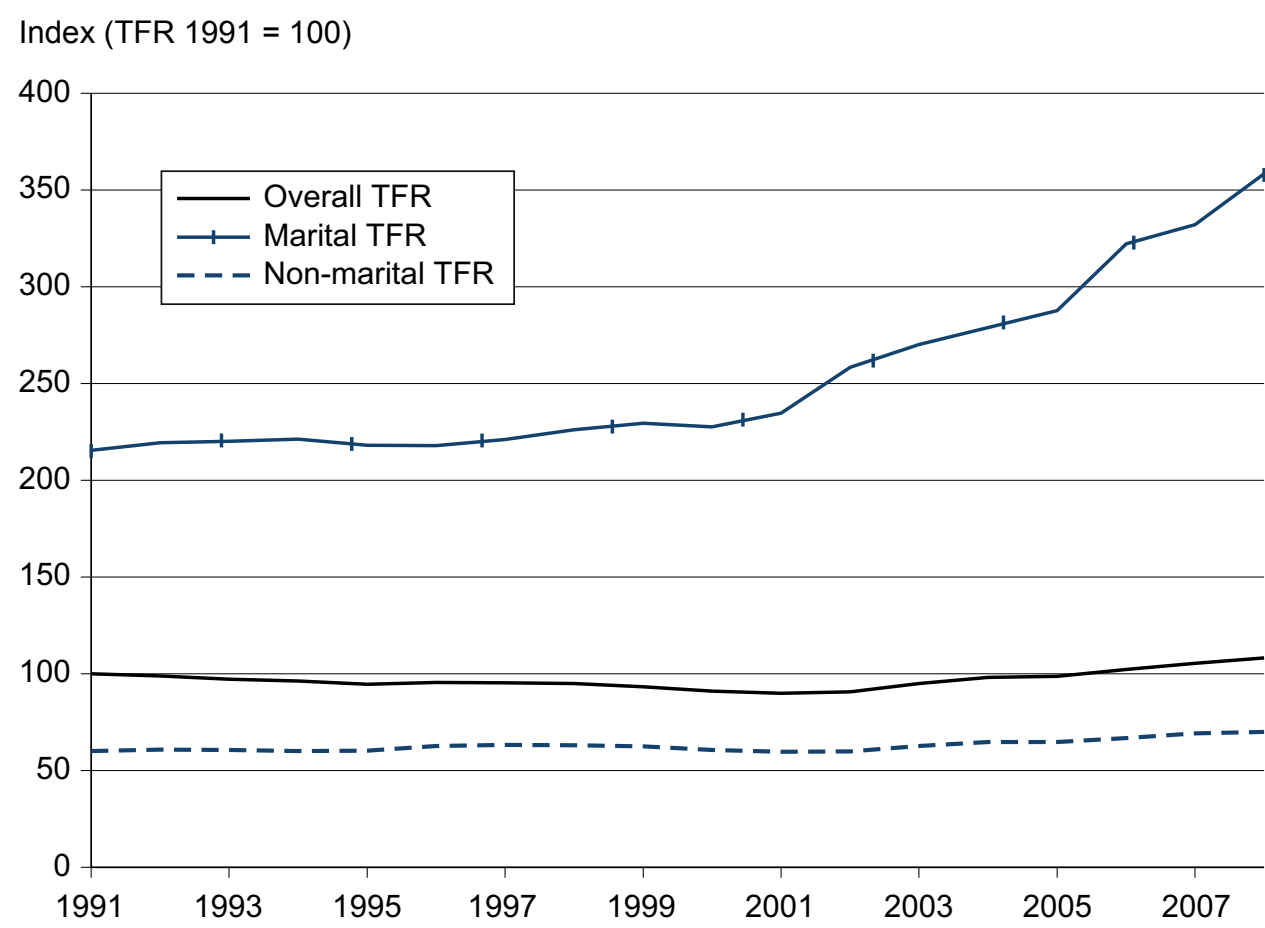

Source: Table 3.1 FM1 Birth statistics, and population estimates by marital status, ONS

In the six years between 2002 and 2008 the TMFR increased rapidly. The TNMFR also increased but at a more modest rate. Thus it would appear that increases in marital fertility have been the main driver of the rising overall TFR since 2001. However this does not explain the increase in the proportion of births outside marriage, since (all other things being equal) rising marital fertility would act to decrease this proportion.

Age-specific fertility rates for married and unmarried women are easier to interpret than the hypothetical TMFR and TNMFR, since they do not assume women to be continually married or unmarried during their lifetimes. Figure 5 examines changes in marital and non-marital fertility by age and shows that there was relatively little change in non-marital fertility rates between 1991 and 2008. However there was a more substantial shift in marital fertility rates at all ages between 2001 and 2008, with marital fertility rates more than doubling in all age groups (except 20-24) over this period. Marital fertility rates were higher than non-marital across the period 1991 to 2008 and across age groups. The exception to this was for women aged 40 and over where non-marital rates were higher between 1991 and 2005. Over the past decade the gap narrowed and between 2006 and 2008 the marital rates for women aged 40 and over overtook the non-marital rates.

The largest rise between 2001 and 2008 in marital fertility was seen for women under 20, although care should be taken in interpreting figures for this age group due to the small numbers of women married at this age ${ }^{15}$. Despite this, women who marry at younger ages tend to have high levels of fertility due to a selection effect (with those women who do choose to marry young, also being those with high fertility preferences $)^{16}$. 


\section{Figure 5 Marital and non-marital age-specific fertility rates by age group, England and Wales, selected years}

Live births per 1,000 women

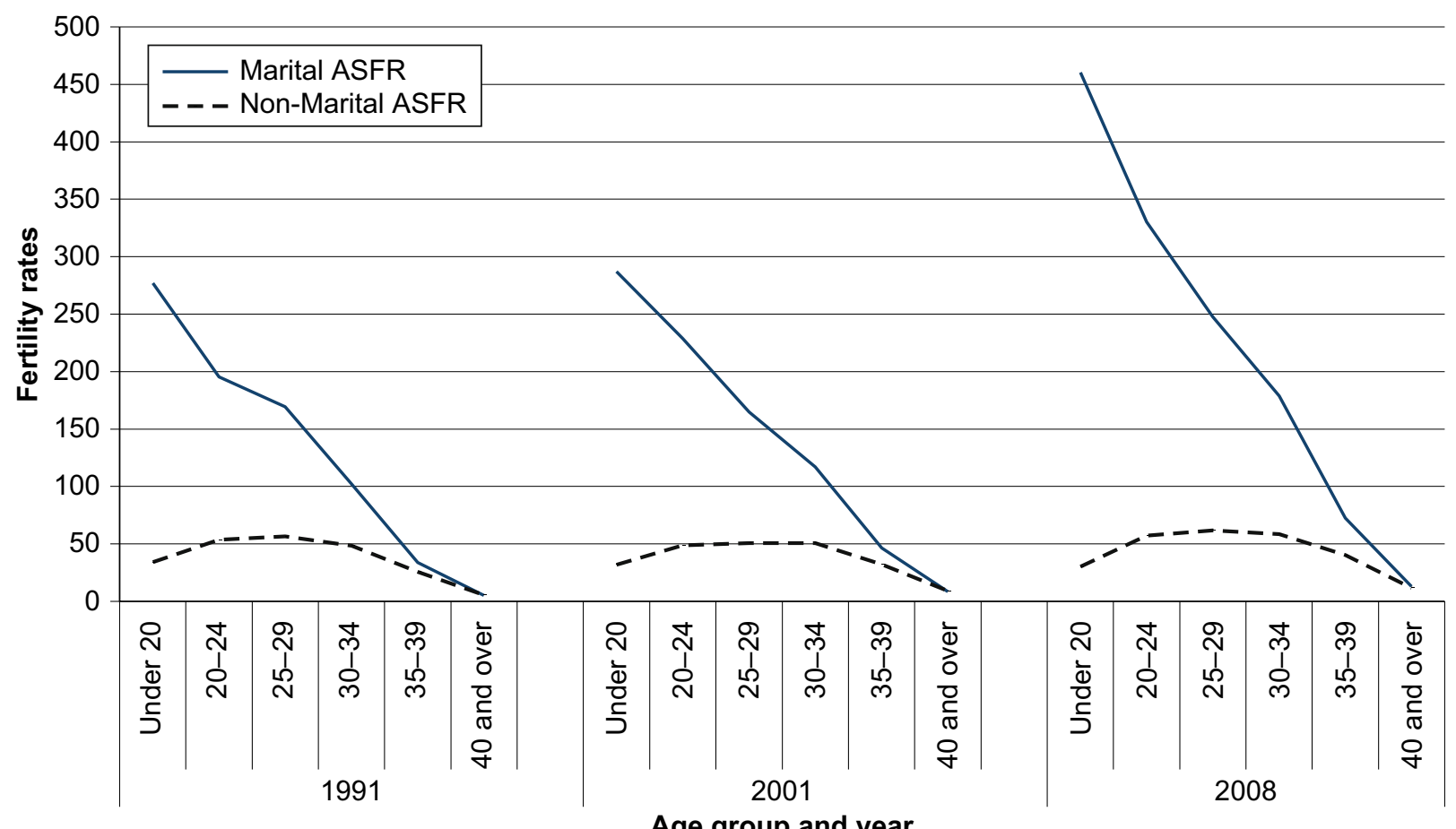

Age group and year

Source: Table 3.1 Birth statistics, FM1 series, and population estimates by marital status, ONS

\section{The proportion of married women}

In 1991, over half (53 per cent) of women of childbearing age were married. Since then the proportion married has steadily fallen, to around one-third of women (34 per cent) by 2008 (Figure 6).

This trend can be seen across all age groups (Figure 7). The larger shift in the proportion of married women at the peak childbearing ages occurred between 1991 and 2001. However the younger age groups experienced larger relative declines in the proportion married than older women.

Another way to consider this shift is by comparing women of a specific age over time. In 1991, a woman aged 30 would have been in the majority if married, as two-thirds (67 per cent) of 30-year old women were married. In 2001 this proportion had fallen to half ( 50 per cent) and by 2008 under two-fifths (38 per cent) of 30-year-olds were married, putting this group firmly in the minority. 
Figure 6 Percentage of women aged 16-44 who are married and not married, England and Wales, selected years

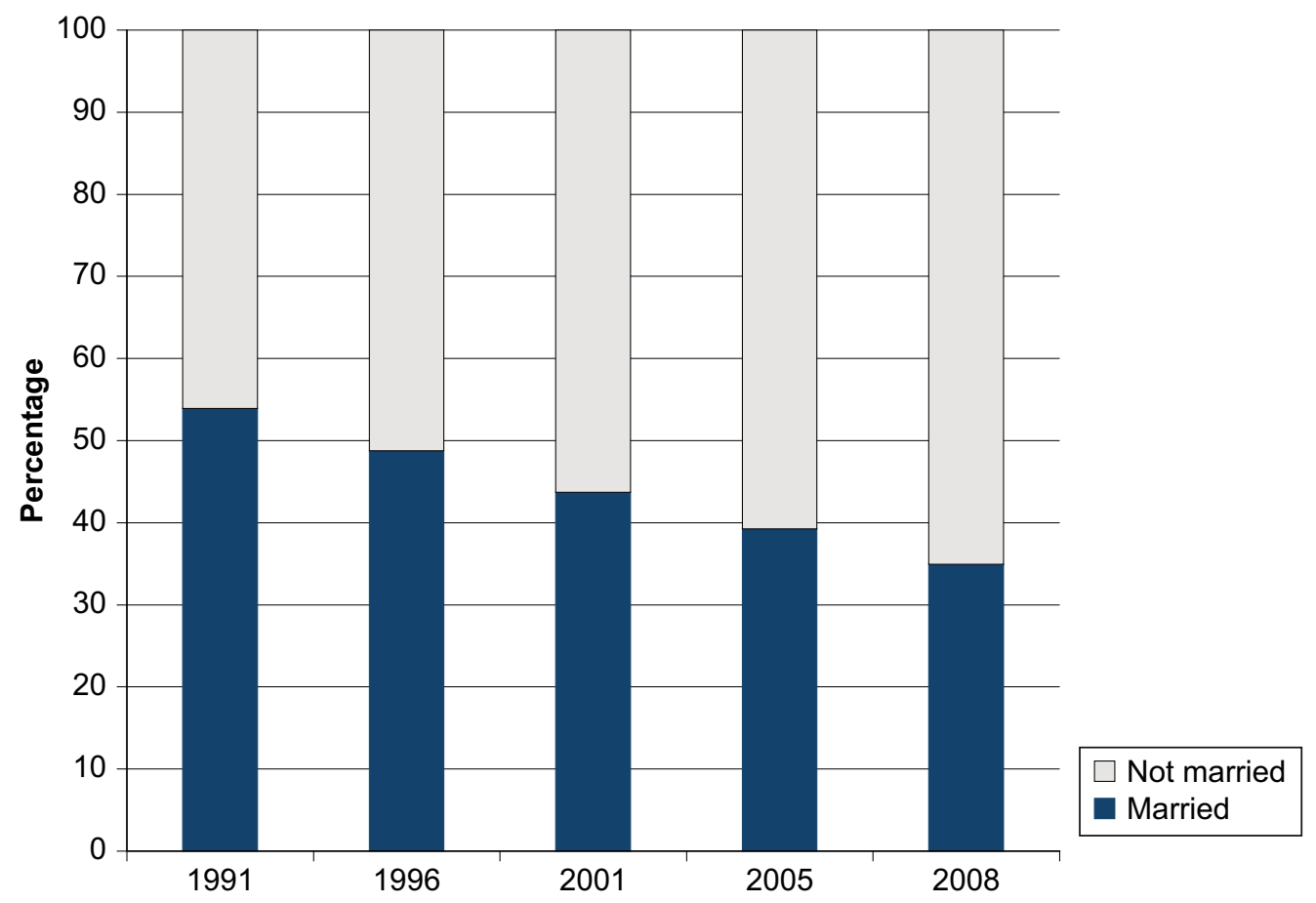

Source: Population estimates by marital status, ONS

Figure $7 \quad$ Percentage of women married by age group, England and Wales, selected years

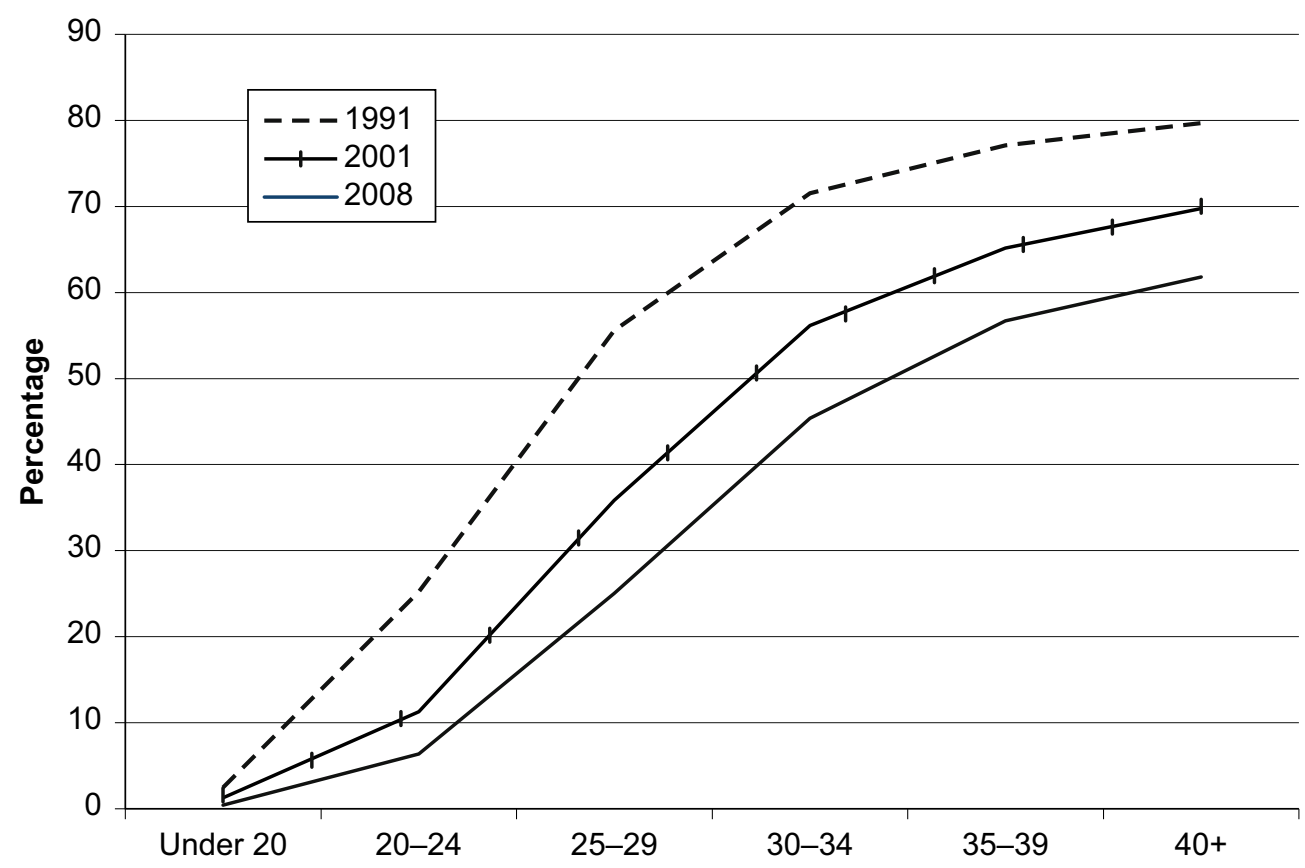

Source: Population estimates by marital status, ONS 


\section{What has driven recent increases in the proportion of births outside marriage?}

To understand what has driven the rise in the proportion of births outside marriage in the two time periods of interest (1991-2001 and 2002-2008), a decomposition analysis has been used to quantify the contribution of four key factors:

- marital fertility rates at each age

- non-marital fertility rates at each age

- population change (size and age structure)

- the proportion of women married at each age

By holding each of these factors constant in turn, the direction and strength of each factors' impact can be assessed, suggesting which has been most important in driving the increasing proportion of non-marital births ${ }^{17}$.

\section{(i) 1991 to 2001}

As might be expected, the decomposition showed that holding the first three factors (marital fertility rates, non-marital fertility rates and population change) at their 1991 levels had small negative impacts on the proportion of births outside marriage (each affecting the expected proportion of births outside marriage by between 1 and 3 percentage points). Holding constant the proportion of women who were married at the 1991 level gave an expected 26 per cent of births outside marriage in 2001, compared with the actual figure of 40 per cent. Therefore the decreasing proportion of women who were married had a large positive impact on the proportion of births outside marriage during the 1990s.

\section{(ii) 2002 to 2008}

As in the 1990s, the decreasing proportion of women who were married acted to increase the proportion of births outside marriage during the period 2002 to 2008 . Holding this factor constant at 2002 levels gives an expected value of 37 per cent of births outside marriage in 2008 (compared with the observed value of 45 per cent). Two other factors, non-marital fertility rates and population change, also exerted small positive influences on the proportion of births outside marriage (holding these factors constant at 2002 levels gave expected 2008 values of 42 and 43 per cent respectively compared with the observed value of 45 per cent).

In contrast, had marital fertility rates remained at 2002 levels, the share of births outside marriage would have been even higher, at 55 per cent, 10 percentage points greater than the actual 2008 figure. This means that increasing marital fertility rates had a negative impact on the proportion of births outside marriage.

From the decomposition analysis we can therefore conclude that:

- The key driver of the increasing proportion of births outside marriage from 1991-2001 and 2002-2008 was the declining proportion of women across all childbearing ages that are married.

- Changes in non-marital fertility rates have had very little impact on the proportion of births outside marriage in either time period.

- Between 2002 and 2008, marital fertility rates have risen and this has dampened the rise in the proportion of births outside marriage. 


\section{Births to unmarried women}

Given the variety of modern living arrangements, it might be considered overly simplistic to only look at births inside and outside marriage in order to understand fertility trends. Unmarried women are not a homogenous group in terms of either partnership or fertility.

From birth registration, it is possible to split births to unmarried women into three groups, but for this article we concentrate on the distinction between births to women who are cohabiting with the baby's father ('cohabiting') and births to women who are not in this type of relationship ('other/ lone'), as follows:

\section{Births outside marriage: Cohabiting}

Births to cohabiting couples are defined as those jointly registered by both parents, where both parents state at registration that they are living at the same address. It can be assumed that such babies are born within a co-residential two-parent family.

\section{Births outside marriage: Other/Lone}

Births that are neither within a married nor a cohabiting relationship are classified as being other/ lone. This category includes: (a) sole registered births (where it may be assumed that such babies are born within a one-parent family), and (b) jointly registered births where parents state that they are living at different addresses ${ }^{18}$.

Other/lone women are assumed not to be living with the child's father, but may or may not be in a relationship (with the father or another partner). The proportion of births to this group has remained relatively stable since 1991, varying between 14 and 16 per cent (Figure 8). The proportion of all babies that were born within a cohabitating union has almost doubled, from 16 per cent in 1991 to 30 per cent in 2008. Therefore, the increase in the proportion of births outside marriage from 1991 to 2008 can partly be attributed to increasing numbers of births to cohabiting women.

There is evidence that some women who would have previously had children within marriage, are now having children within cohabiting unions. Official statistics and academic research point towards this societal shift and the rising popularity of cohabitation, both as precursor to, but also as a replacement for marriage ${ }^{19}$. It is because of this trend that cohabitation is often expected to explain recent increases in non-marital births.

Increases in the proportion of births within cohabiting unions have occurred across all age groups (Figure 9). In both 1991 and 2008, women in their early thirties were the least likely to have a birth in a cohabiting relationship, reflecting the high proportion of marital births in this age group. In 1991 , women under 20 had the highest proportion of cohabiting births but by 2008 this had shifted to women aged 20-24. This reflects the trend towards delayed childbearing.

Data on changes in births over time by partnership status are given in Appendix Tables A2 and A3. These show changes in the number of births between 1991 and 2001, and between 2001 and 2008. Although the number of births to married and other/lone women fell between 1991 and 2001 (causing an overall decline in the number of births), the number of births to cohabiting women increased, especially among women in their thirties. Between 2002 and 2008, over half (52 per cent) of the overall increase in births was accounted for by births to cohabiting women, with the largest increases among women in their twenties. 
Figure 8 Percentage of live births to married, cohabiting and otherl lone women, England and Wales, selected years

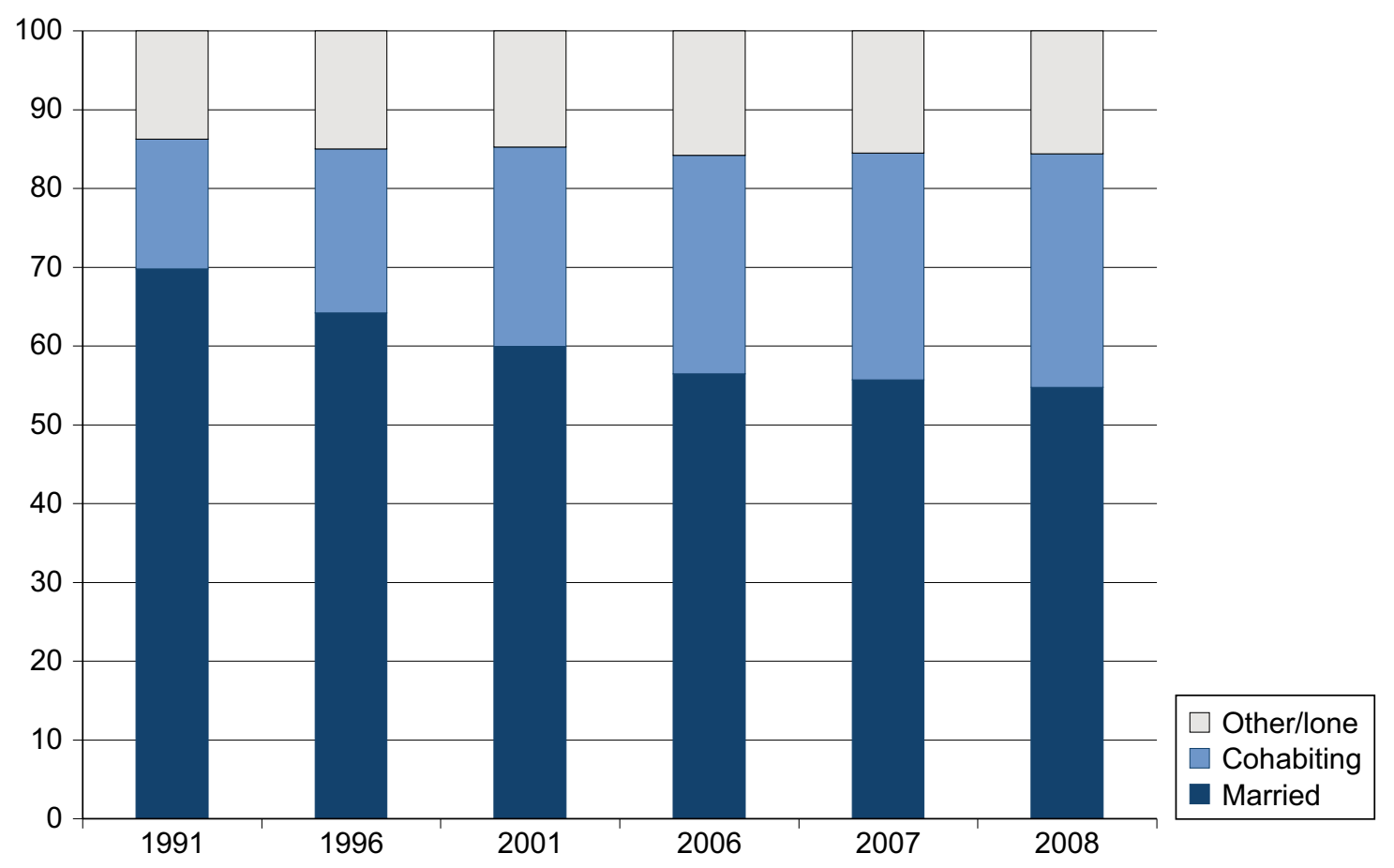

Source: Tables 3.9 and 3.10, FM1 Birth Statistics, 2001 and 2008, Office for National Statistics

Figure 9 Percentage of births to mothers in a cohabiting relationship by age group of mother, England and Wales, selected years

Percentage

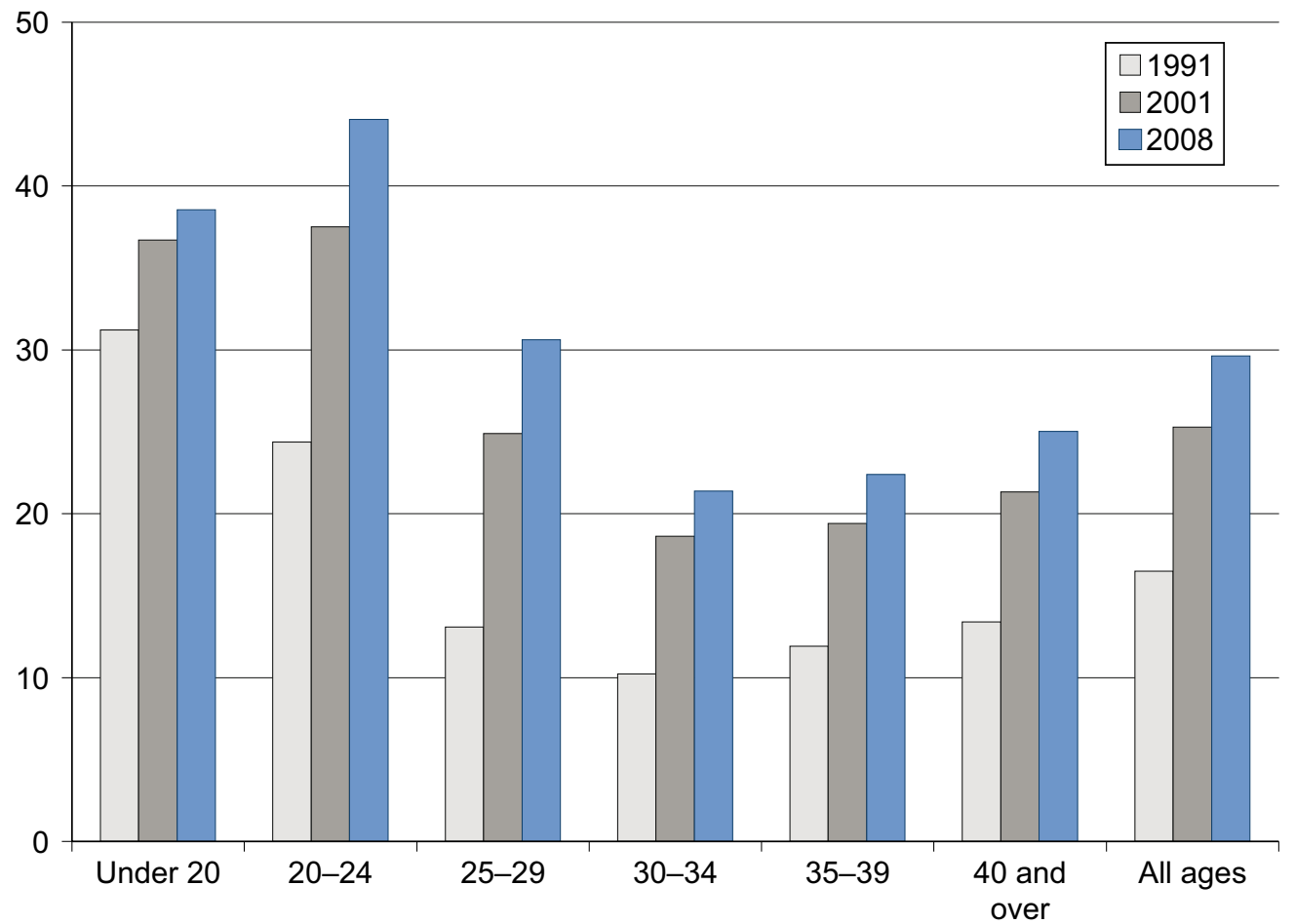

Note: The data underpinning this figure are available in Appendix Table A1 


\section{Estimating the female population by partnership status}

In order to produce fertility rates for cohabiting women (as well as married and other/lone women), it is necessary to subdivide the female population by partnership status to obtain appropriate denominators. In this article, two data sources are used for this purpose: (a) population estimates by marital status, and (b) estimates of the cohabiting population. Analysis here focuses on the female population aged $16-44$.

\section{Population Estimates by Marital Status}

ONS publishes mid-year estimates of the population by marital status by age and sex (for persons living in England and Wales) ${ }^{20}$. These estimates refer to legal marital status and use the following categories: single, married, divorced and widowed. Using these estimates, the female population of childbearing age can be split into the 'married' and the 'unmarried', the latter consisting of the single, divorced and widowed. In the legal marital status estimates, people who are separated (but legally married) are included in the married population.

\section{Cohabitation Estimates}

Estimates of the cohabiting population are prepared periodically by ONS using survey data ${ }^{21}$. The proportion of adults living in a cohabitating relationship has been estimated for the years 1992, 1996, 2003 and 2007. This article also uses data on the female cohabiting population from the 2001 Census as an additional year for examining trends ${ }^{22}$. The methodology for estimating the cohabiting population in these years is explained fully elsewhere ${ }^{23}$.

Using these estimates, the 'unmarried' female population of childbearing age can be subdivided into:

(i) Cohabiting women: the population of unmarried women (whose legal marital status is nevermarried, divorced or widowed) aged 16-44 who are living with a partner.

(ii) Other/lone women: the population of unmarried women (whose legal marital status is nevermarried, divorced or widowed) aged 16-44 who are not living with a partner.

For the purposes of this article, categories need to be mutually exclusive, so separated women have been included within the married population and excluded from the populations of cohabiting and other/lone women ${ }^{24}$. The main reason for this is so that marital fertility rates in this article are consistent with figures published elsewhere ${ }^{25}$. Additional analysis was carried out to compare estimated fertility rates by partnership status for 2007 when the separated are included in the married population (as opposed to including them in the unmarried population). The results found minimal variation overall, although there were some small differences at older ages ${ }^{26}$.

Figure 10 shows the decreasing percentage of married women over time relative to the increases in the percentage of cohabiting and other/lone women. The most recently available cohabitation estimates for 2007 showed that 17 per cent of women aged 16-44 were cohabiting, an increase of 6 percentage points since 1992 when the figure was 11 per cent. The rising proportion of women cohabiting has not entirely made up for the reduction in women married, hence the proportion of women of childbearing age that are not in a marital or cohabiting partnership has risen from 36 per cent in 1992 to 46 per cent in 2007. 


\section{Figure 10 Percentage of women aged 16-44 by marital status, England and Wales, selected years}

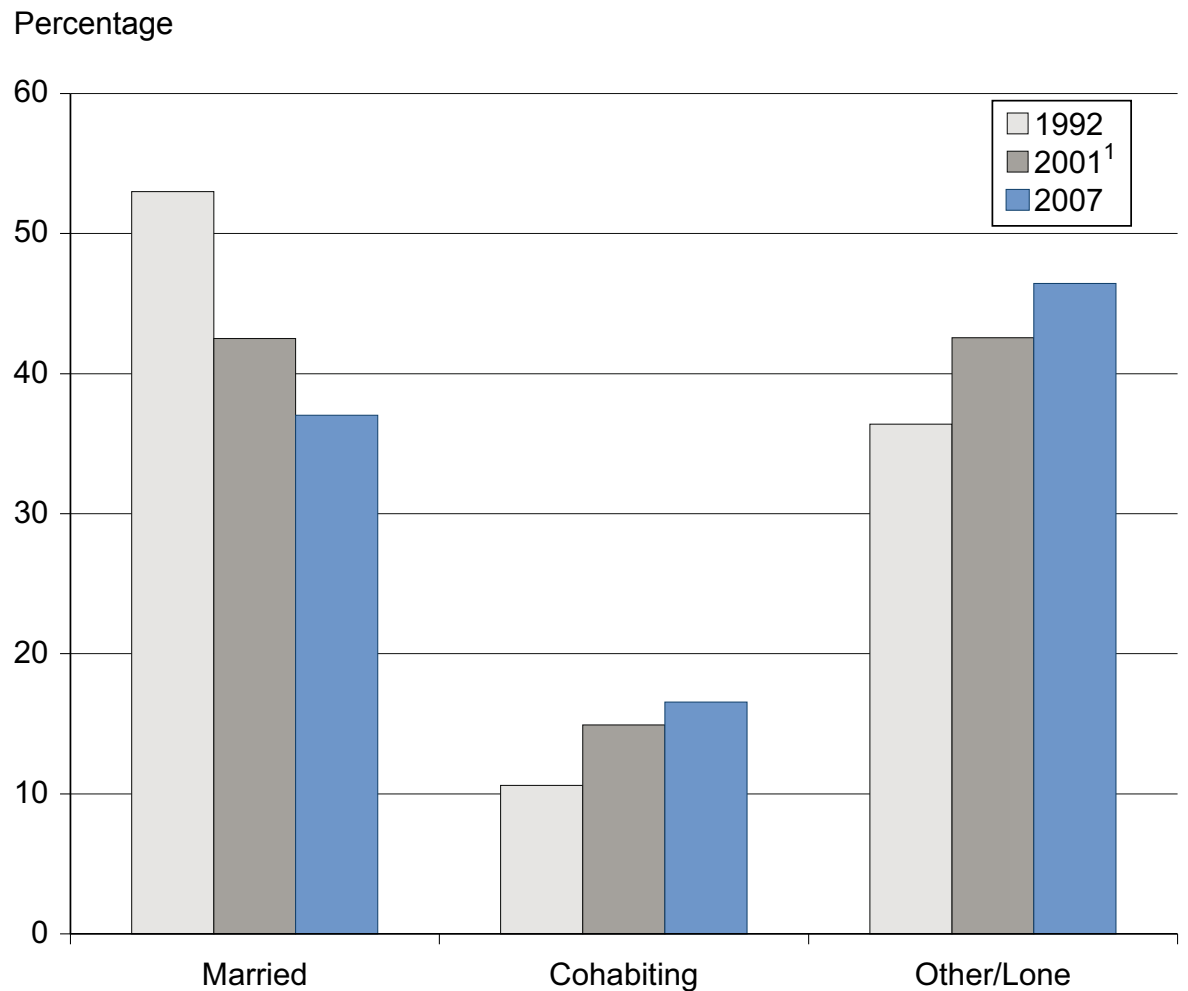

1 The cohabiting and other/lone population for 2001 has been derived from the 2001 Census. The populations for 1992 and 2007 have been derived from cohabitation estimates (see main text).

Note: The data underpinning this figure are available in Appendix Table A4

Further information on the female population by partnership status is given in Appendix Tables A5 and A6. These are similar to Tables A2 and A3 (for births) and show changes in the population by age group between 1992 and 2001 (Table A5) and between 2001 and 2007 (Table A6). Broadly, these tables show that during the 1990s there was an increase in the cohabiting and other/lone populations, particularly at older ages. The trend is not so clear between 2001 and 2007, when increases in these population groups were mainly at younger ages, particularly for the other/lone. The married population fell for most age groups between 2001 and 2007, especially for the ages 25 to 39 .

These large shifts in partnership status over the course of two decades imply that, compared with the early 1990s, a smaller proportion of women in 2007 will be married and therefore 'at risk' of having a birth within marriage, and larger proportions will be 'at risk' of a cohabiting birth or other/ lone birth. Partnership changes may affect fertility rates within each of these three groups, even in the absence of changes to underlying fertility. Consider, for example, the group of women who in the past might have chosen to be married but nowadays choose instead to cohabit. If this group has lower fertility than the married, but higher fertility than those who are not living with a partner, the change in partnership status over time could lead to a rise in both marital and cohabiting fertility rates purely due to a compositional effect ${ }^{27}$. If this were the case, we might expect to see an increase in fertility among cohabiting women over time as this population becomes less selective. As Martin (2009) notes, "the decline of marriage has moved into unmarried status a population of women very different from women who were single a generation ago..... this changing composition 
of the single population has changed the aggregate behaviour of single women, the cultural expectations of single women and women's decisions to cohabit or marry."28

\section{Fertility rates by partnership status}

When calculating fertility rates the events in the numerator (number of births) need to correspond to the population included in the denominator (number of women 'at risk' of a birth of that type). Information on the numerators and denominators chosen to estimate rates by partnership status is given in Box two.

\section{Box two Fertility rates by partnership status}

Births by partnership status and population estimates by partnership status for females of childbearing age have been used to produce age-specific and total fertility rates for the following groups:

\section{Marital fertility rates}

Numerator: births within marriage

Denominator: legally married female population (aged 16-44)

\section{Non-marital fertility rates}

Numerator: births outside marriage

Denominator: single, divorced and widowed population (aged 16-44)

Non-marital fertility rates are further divided into:

\section{Cohabiting fertility rates}

Numerator: jointly registered births to parents living at the same address

Denominator: unmarried cohabiting women (aged 16-44).

\section{Other/lone fertility rates}

Numerator: jointly registered births to parents living at different addresses and births registered solely by the mother

Denominator: unmarried women (aged 16-44) who are not cohabiting.

There are two issues of correspondence here. First, it is only legal for women resident in England and Wales to marry (with parental consent) from ages 16 and above. Therefore, population denominators used here start at age 16 although births to mothers under 16 are included ${ }^{29}$. Second, there may also be discrepancies between the numerator and the denominator in specific cases. One example is the case of a woman who is separated from her husband and cohabiting with a new partner who is the child's father - the birth is likely to be registered jointly and assumed to be within a cohabitation, but legally the woman is still married and part of the denominator for the marital fertility rate ${ }^{30}$. Similarly, if a small proportion of sole registered births are actually born to cohabiting couples (but registered as sole), then cohabiting fertility rates may be slightly underestimated and other/lone fertility rates slightly over-estimated. 


\section{Figure 11 Estimated total fertility rates by partnership status and by quinary age groups, indexed rates, England and Wales, selected years}

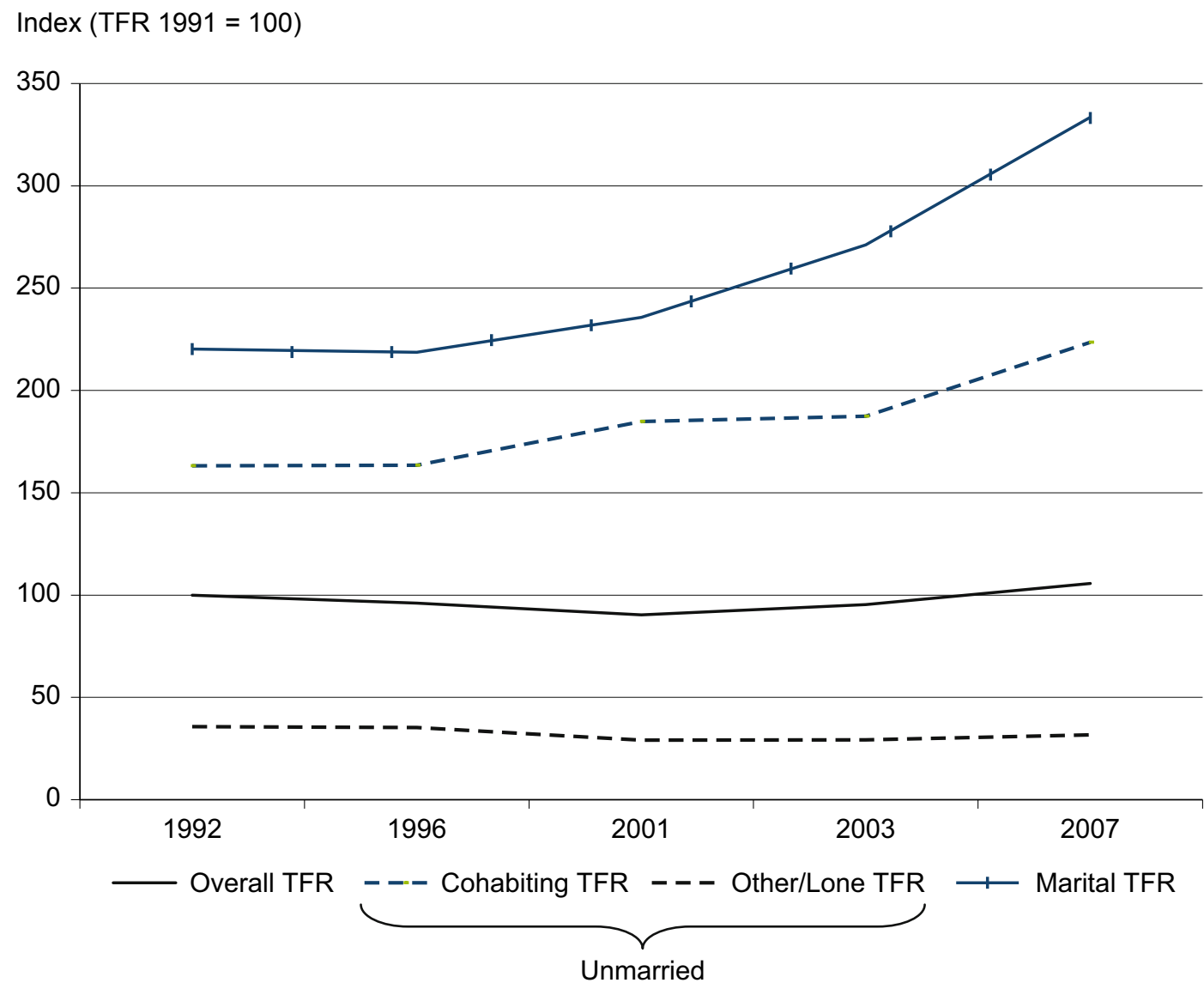

1 For the 2001 cohabitating and other/lone TFRs, the population denominator used was derived from the 2001 Census. For the remaining years, cohabitation estimates were used.

2 The 2003 cohabitation estimates have not been adjusted to take account of revised marriages abroad figures. The cohabitating and other/lone TFRs presented here are therefore slightly overestimated.

Source: Authors'own calculations

As noted previously, total fertility rates by partnership status are somewhat artificial (for example the TFR for cohabiting women is based on a hypothetical woman who cohabits continuously from age 16 to 44). However, total fertility rates for cohabiting women are estimated here to provide an understanding of how the fertility of cohabiting women compares with that of married and other/ lone women.

Figure 11 shows that during the past two decades the estimated TFR for cohabiting women has been below that for married women, but well above the overall TFR. In contrast the TFR for other/ lone women in $\mathbf{2 0 0 7}$ was well below the level for non-married women.

Estimated total fertility among cohabiting women has risen over time, largely in step with the increase in marital fertility; although the 2001 estimate (based on a Census denominator) may be slightly out of line with the rest of the time series ${ }^{31}$, it is clear that the rise in the overall TFR in England and Wales since 2001 has been driven by increasing fertility among both married and cohabiting women, not just by married women as may previously have been assumed. 


\section{Figure 12 Fertility rates by partnership status and age group, England and Wales, selected years}

Live births per 1,000 women aged $16-44$

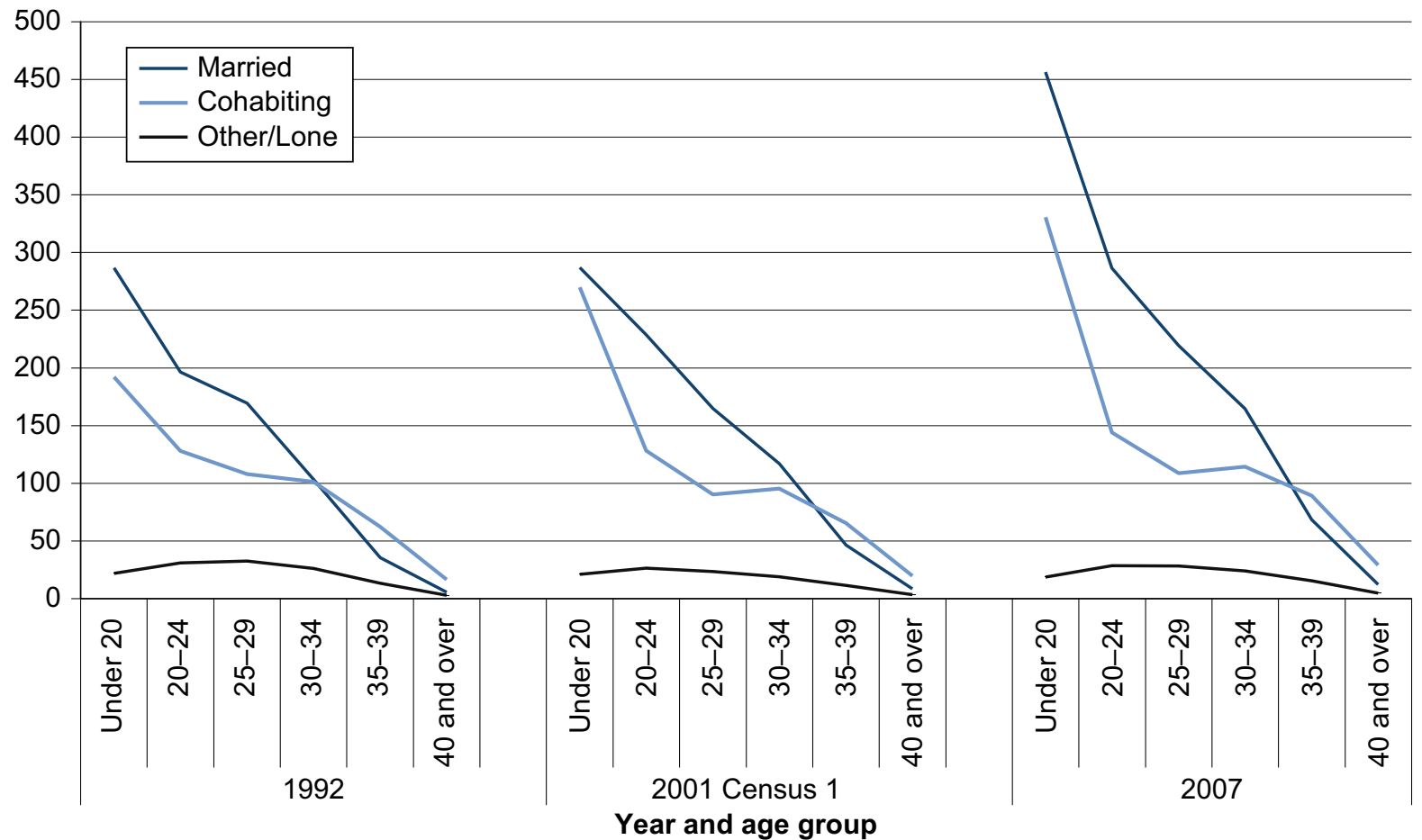

1 For the 2001 cohabitation and other/lone ASFRs, the population denominator used was derived from the 2001 Census. For the other years cohabitation estimates were used.

Note: The data underpinning this figure are available in Appendix Table B1.

Source: Authors'own calculations

Age-specific fertility rates (ASFRs) give a more meaningful picture of fertility among the married and cohabiting than TFRs, as they do not assume women to be partnered throughout their childbearing lives. Figure 12 shows ASFRs for married, cohabiting and other/lone women in three selected years (the data behind Figure 12 can be found in Appendix Table B1).

In 2007, fertility rates for cohabiting women were below those for married women in all age groups below age $35^{32}$. For example, fertility rates for women in their twenties were twice as high among the married as among the cohabiting. At age 30-34, fertility rates for married women were 44 per cent higher than for cohabiting women.

In contrast, at ages 35-39 and over 40, fertility rates for cohabiting women were higher than for married women. In 2007 the fertility rates of cohabiting women aged 35-39 were 1.3 times higher than for married women of the same age. Among women aged 40 and over, fertility rates were 2.4 times higher for cohabiting women than for married ${ }^{33}$. One possible explanation for this could be post-marital fertility, where older women re-partner informally following divorce and have a child within their new union. An alternative explanation is that those women who choose to cohabit as a substitute to marriage might leave their childbearing until later in life (compared with the married) for a variety of reasons. This variation in the timing of births may be attributable to differences in the socio-economic profile of the two groups. However in practice the two groups are not distinct: 
for example women who cohabit in their twenties and delay their childbearing, due to higher education and employment, may be the same women who later marry and have children as they move into their thirties.

Unsurprisingly, fertility rates among other/lone women are considerably lower than those for cohabiting women in 2007. Fertility rates in this group are highest among women in their twenties and show a similar curve to the non-marital fertility rates in Figure 5, though at a lower level.

The 2007 age pattern of fertility in each group is also evident in 1992 and 2001. Fertility rates for cohabiting women in the peak childbearing ages (25-29 and 30-34) fell slightly between 1992 and 2001 , and then increased to a higher level by 2007 . The largest relative increases in the fertility of cohabiting women from 2001 to 2007 occurred among women 35 and over. For example there were 20 births per 1,000 cohabiting women aged 40 and over in 2001; this rose to 29 per 1,000 by 2007. The gap between the marital and cohabiting rates for older women has narrowed - in 1992 the fertility rates of cohabiting women aged 35-39 were 80 per cent higher than for married women of the same age, while in 2007 they were only 30 per cent higher.

\section{Discussion}

The family context in which babies are born and children grow up is of continuing interest to policy-makers. This article has highlighted some material changes in family context for babies born in England and Wales. Over the last two decades, there has been a large shift in the type of partnerships within which couples have children, with smaller proportions of births occurring to married parents and larger proportions to cohabiting parents. But despite this change, the proportion of babies born to two parents living together (married or unmarried) has remained remarkably stable since 1991 at around 85 per cent.

From a methodological viewpoint, this article has presented initial estimates of fertility for cohabiting women by calendar year and enabled comparison of the fertility of different groups on a period basis for the first time. The approach taken here has clear limitations, with both the numerators and denominator (survey estimates of current partnership status) subject to various caveats. An alternative approach would be to produce annual estimates from survey data containing retrospective birth and union histories (such as the ONS General Lifestyle Survey). This would have the advantage of consistency in source between numerator and denominator, but sample size is a likely constraint.

Substantively, this article has shown that over the past two decades, cohabiting women in England and Wales have had an overall level of fertility below that of married women but considerably above that of other unmarried women. In addition, the age pattern of fertility among the cohabiting is similar to that of married women, although above age 35, cohabiting women have slightly higher fertility than the married. This has a potential bearing on policy, for example in the provision of services to new parents. In terms of explaining the rising TFR since 2001, both married and cohabiting women have contributed to the rise, a finding which adds to the knowledge base for fertility assumptions made by ONS in the National Population Projections. 
Cross-sectional analyses such as these give a valuable indication of changes in the aggregate relationship between fertility and cohabitation over time. However they cannot inform us about the transitions between different partnership states and parities at the individual level (and the complex inter-relationships between these processes). These issues are best investigated using retrospective or cohort data that follow individuals over time. For example, recent research based on the 1958 and 1970 cohort studies in Britain concluded that the increase in childbearing among cohabiting couples was due to these couples being increasingly likely to stay together without marrying, as opposed to either separating or getting married ${ }^{34}$.

Data collected at birth registration in England and Wales will be affected by recent and forthcoming legislative changes. From 2009, the Human Fertilisation and Embryology Act (2008) has enabled births to be registered to a mother and a second female parent, effectively creating a new recorded partnership type ${ }^{35}$. From 2011, the Welfare Reform Act will make joint birth registration a legal requirement for all unmarried parents except where the registrar decides this is impossible, impracticable or unreasonable ${ }^{36}$. This change is expected to decrease the proportion of sole registrations and increase the proportion of joint registrations. However the impact on analysis of births to cohabiting and lone women is likely to be minimal if the majority of births affected are to women not living with the father; such births would still be classed as 'lone'.

Alongside this, two amendments have recently been made to the Population (Statistics) Act 1938 and are due for implementation during $2011^{37}$. The main amendment will enable information on the number of previous children to be collected from all women (instead of just married women as at present). The second is to require all women to be asked at birth registration whether they have previously been married or in a civil partnership, enabling (for the first time) the distinction to be made between births outside marriage to single women and births to those divorced, widowed or previously in a civil partnership. Analysis of this new information will mean that a wider range of research questions can be addressed, including whether births to older women in cohabiting unions are predominantly first and second births to women who have never married, or higher order births to women who were previously married but are now cohabiting with a new partner. 


\section{Key findings}

- In England and Wales, the proportion of babies born to two parents living together, married or unmarried, has remained stable at around 85 per cent over the last two decades.

- The proportion of births to married parents decreased from 70 per cent in 1991 to 55 per cent in 2008. This change is mainly due to the decreasing proportion of women of childbearing age who are married.

- During the 1990s the proportion of women of childbearing age who were cohabiting increased, particularly among those aged 25 and over. The cohabiting population also increased between 2001 and 2007, but at a slower pace.

- Between 1991 and 2001, births to cohabiting women increased, especially among women in their thirties, despite an overall decline in the number of births during this period.

- From 2002 to 2008, over half (52 per cent) of the overall increase in births was accounted for by cohabiting women, with the largest increases among women in their twenties.

- Over the past two decades, cohabiting women in England and Wales have had an overall level of fertility below that of married women and considerably above that of other unmarried women.

- In 2007, fertility rates for women in their twenties were twice as high among the married as among the cohabiting. At age 30-34, fertility rates for married women were 44 per cent higher than for cohabiting women.

- At older ages, cohabiting women have higher fertility than married women. In 2007, the fertility rates of cohabiting women aged 35-39 were 1.3 times higher than for married women of the same age.

- The rising TFR in England and Wales since 2001 has been driven by increasing fertility among both married and cohabiting women.

\section{Acknowledgements}

The authors acknowledge the useful comments from ONS colleagues, and anonymous referees on this article. 
Appendix A

Changes in live births and population by partnership status

Table A1 Number of live births in 1991, 2001 and 2008 by partnership status, England and Wales

\begin{tabular}{|c|c|c|c|c|}
\hline & \multicolumn{4}{|c|}{1991} \\
\hline & $\begin{array}{c}\text { Married } \\
\text { women }\end{array}$ & $\begin{array}{r}\text { Cohabiting } \\
\text { women }\end{array}$ & Others & Total \\
\hline Under 20 & 8,948 & 16,351 & 27,097 & 52,396 \\
\hline $20-24$ & 95,605 & 42,245 & 35,506 & 173,356 \\
\hline $25-29$ & 196,281 & 32,532 & 19,914 & 248,727 \\
\hline $30-34$ & 135,542 & 16,468 & 9,249 & 161,259 \\
\hline 35-39 & 43,810 & 6,385 & 3,449 & 53,644 \\
\hline 40 and over & 7,737 & 1,317 & 781 & 9,835 \\
\hline \multirow[t]{3}{*}{ All ages } & 487,923 & 115,298 & 95,996 & 699,217 \\
\hline & \multicolumn{4}{|c|}{2001} \\
\hline & $\begin{array}{l}\text { Married } \\
\text { women }\end{array}$ & $\begin{array}{r}\text { Cohabiting } \\
\text { women }\end{array}$ & Others & Total \\
\hline Under 20 & 4,640 & 16,215 & 23,334 & 44,189 \\
\hline $20-24$ & 40,736 & 40,843 & 27,265 & 108,844 \\
\hline $25-29$ & 103,131 & 39,797 & 16,998 & 159,926 \\
\hline $30-34$ & 133,710 & 33,306 & 11,904 & 178,920 \\
\hline $35-39$ & 63,202 & 16,790 & 6,503 & 86,495 \\
\hline 40 and over & 11,129 & 3,470 & 1,661 & 16,260 \\
\hline \multirow[t]{3}{*}{ All ages } & 356,548 & 150,421 & 87,665 & 594,634 \\
\hline & \multicolumn{4}{|c|}{2008} \\
\hline & $\begin{array}{c}\text { Married } \\
\text { women }\end{array}$ & $\begin{array}{r}\text { Cohabiting } \\
\text { women }\end{array}$ & Others & Total \\
\hline Under 20 & 2,739 & 17,231 & 24,721 & 44,691 \\
\hline $20-24$ & 38,239 & 59,913 & 37,819 & 135,971 \\
\hline $25-29$ & 110,353 & 59,104 & 23,503 & 192,960 \\
\hline $30-34$ & 138,066 & 41,178 & 13,206 & 192,450 \\
\hline $35-39$ & 81,602 & 26,036 & 8,582 & 116,220 \\
\hline 40 and over & 16,931 & 6,614 & 2,874 & 26,419 \\
\hline All ages & 387,930 & 210,076 & 110,705 & 708,711 \\
\hline
\end{tabular}

Source: Tables 3.9 and 3.10, FM1 Birth Statistics, historical data series, Office for National Statistics 
Table A2 Changes in the number of live births between 1991 and 2001 by partnership status, England and Wales

\begin{tabular}{lrrrr}
\hline & $\begin{array}{c}\text { Married } \\
\text { women }\end{array}$ & $\begin{array}{r}\text { Cohabiting } \\
\text { women }\end{array}$ & Others & Total \\
\hline Under 20 & $-4,308$ & -136 & $-3,763$ & $-8,207$ \\
$20-24$ & $-54,869$ & $-1,402$ & $-8,241$ & $-64,512$ \\
$25-29$ & $-93,150$ & 7,265 & $-2,916$ & $-88,801$ \\
$30-34$ & $-1,832$ & 16,838 & 2,655 & 17,661 \\
$35-39$ & 19,392 & 10,405 & 3,054 & 32,851 \\
40 and over & 3,392 & 2,153 & 880 & 6,425 \\
All ages & $-\mathbf{1 3 1 , 3 7 5}$ & $\mathbf{3 5 , 1 2 3}$ & $\mathbf{- 8 , 3 3 1}$ & $\mathbf{- 1 0 4 , 5 8 3}$ \\
\hline
\end{tabular}

Source: Tables 3.9 and 3.10, FM1 Birth Statistics, historical data series, Office for National Statistics

Table A3 Changes in the number of live births between 2001 and 2008 by partnership status, England and Wales

\begin{tabular}{lrrrr}
\hline & $\begin{array}{c}\text { Married } \\
\text { women }\end{array}$ & $\begin{array}{r}\text { Cohabiting } \\
\text { women }\end{array}$ & Others & Total \\
\hline Under 20 & $-1,901$ & 1,016 & 1,387 & 502 \\
$20-24$ & $-2,497$ & 19,070 & 10,554 & 27,127 \\
$25-29$ & 7,222 & 19,307 & 6,505 & 33,034 \\
$30-34$ & 4,356 & 7,872 & 1,302 & 13,530 \\
$35-39$ & 18,400 & 9,246 & 2,079 & 29,725 \\
40 and over & 5,802 & 3,144 & 1,213 & 10,159 \\
All ages & $\mathbf{3 1 , 3 8 2}$ & $\mathbf{5 9 , 6 5 5}$ & $\mathbf{2 3 , 0 4 0}$ & $\mathbf{1 1 4 , 0 7 7}$ \\
\hline
\end{tabular}

Source: Tables 3.9 and 3.10, FM1 Birth Statistics, historical data series, Office for National Statistics 


\section{Table A4 Female population aged 16-44 in 1992, 2001 and 2007 by} partnership status, England and Wales

\begin{tabular}{|c|c|c|c|c|}
\hline & \multicolumn{4}{|c|}{1992} \\
\hline & $\begin{array}{l}\text { Married } \\
\text { women }\end{array}$ & $\begin{array}{l}\text { Cohabiting } \\
\text { women }\end{array}$ & Others & Total \\
\hline Under 20 & 27,200 & 79,300 & $1,128,600$ & $1,235,100$ \\
\hline $20-24$ & 439,200 & 328,900 & $1,128,600$ & $1,896,600$ \\
\hline $25-29$ & $1,114,800$ & 322,100 & 645,200 & $2,082,000$ \\
\hline $30-34$ & $1,334,800$ & 184,600 & 390,100 & $1,909,400$ \\
\hline $35-39$ & $1,289,700$ & 112,600 & 293,200 & $1,695,500$ \\
\hline 40 and over & $1,379,300$ & 90,500 & 285,900 & $1,755,700$ \\
\hline \multirow[t]{3}{*}{ All ages } & $5,584,900$ & $1,118,000$ & $3,871,600$ & $10,574,500$ \\
\hline & \multicolumn{4}{|c|}{$2001^{1}$} \\
\hline & $\begin{array}{l}\text { Married } \\
\text { women }\end{array}$ & $\begin{array}{r}\text { Cohabiting } \\
\text { women }\end{array}$ & Others & Total \\
\hline Under 20 & 16,200 & 60,100 & $1,104,300$ & $1,180,600$ \\
\hline $20-24$ & 178,000 & 318,700 & $1,027,200$ & $1,523,900$ \\
\hline $25-29$ & 625,400 & 440,400 & 721,200 & $1,787,000$ \\
\hline $30-34$ & $1,142,400$ & 349,500 & 626,500 & $2,118,300$ \\
\hline $35-39$ & $1,356,300$ & 256,400 & 565,600 & $2,178,200$ \\
\hline 40 and over & $1,292,900$ & 175,100 & 466,500 & $1,934,500$ \\
\hline \multirow[t]{3}{*}{ All ages } & $4,611,100$ & $1,600,180$ & $4,511,300$ & $10,722,600$ \\
\hline & \multicolumn{4}{|c|}{2007} \\
\hline & $\begin{array}{l}\text { Married } \\
\text { women }\end{array}$ & $\begin{array}{r}\text { Cohabiting } \\
\text { women }\end{array}$ & Others & Total \\
\hline Under 20 & 6,800 & 51,500 & $1,327,500$ & $1,385,800$ \\
\hline $20-24$ & 135,600 & 388,300 & $1,256,200$ & $1,780,200$ \\
\hline $25-29$ & 486,200 & 496,800 & 772,600 & $1,755,600$ \\
\hline $30-34$ & 839,600 & 347,700 & 547,400 & $1,734,800$ \\
\hline $35-39$ & $1,191,300$ & 284,800 & 551,600 & $2,027,700$ \\
\hline 40 and over & $1,334,100$ & 216,200 & 554,200 & $2,104,500$ \\
\hline All ages & $3,993,700$ & $1,785,400$ & $5,009,500$ & $10,788,600$ \\
\hline
\end{tabular}

Note: Figures may not add up exactly due to rounding

1 The cohabiting and other/lone population for 2001 has been derived from the 2001 Census.

The populations for 1992 and 2007 have been derived from cohabitation estimates. 
Table A5 Changes in the female population aged 16-44 between 1992 and 2001 by partnership status, England and Wales

\begin{tabular}{lrrrr}
\hline & $\begin{array}{c}\text { Married } \\
\text { women }\end{array}$ & $\begin{array}{r}\text { Cohabiting } \\
\text { women }\end{array}$ & Other/lone & Total \\
\hline Under 20 & $-11,000$ & $-19,200$ & $-24,300$ & $-54,500$ \\
$20-24$ & $-261,200$ & $-10,200$ & $-101,400$ & $-372,700$ \\
$25-29$ & $-489,400$ & 118,300 & 76,000 & $-295,000$ \\
$30-34$ & $-192,400$ & 164,900 & 236,400 & 208,900 \\
$35-39$ & 66,600 & 143,800 & 272,400 & 482,700 \\
40 and over & $-86,400$ & 84,600 & 180,600 & 178,800 \\
All ages & $\mathbf{- 9 7 3 , 8 0 0}$ & $\mathbf{4 8 2 , 1 8 0}$ & $\mathbf{6 3 9 , 7 0 0}$ & $\mathbf{1 4 8 , 1 0 0}$ \\
\hline
\end{tabular}

Note: Figures may not add up exactly due to rounding

The cohabiting and other/lone population for 2001 has been derived from the 2001 Census.

The populations for 1992 have been derived from cohabitation estimates.

Table A6 Changes in the female population aged 16-44 between 2001 and 2007 by partnership status, England and Wales

\begin{tabular}{lrrrr}
\hline & $\begin{array}{c}\text { Married } \\
\text { women }\end{array}$ & $\begin{array}{r}\text { Cohabiting } \\
\text { women }\end{array}$ & Other/lone & Total \\
\hline Under 20 & $-9,400$ & $-8,600$ & 223,200 & 205,200 \\
$20-24$ & $-42,400$ & 69,600 & 229,000 & 256,300 \\
$25-29$ & $-139,200$ & 56,400 & 51,400 & $-31,400$ \\
$30-34$ & $-302,800$ & $-1,800$ & $-79,100$ & $-383,500$ \\
$35-39$ & $-165,000$ & 28,400 & $-14,000$ & $-150,500$ \\
40 and over & 41,200 & 41,100 & 87,700 & 170,000 \\
All ages & $-617,400$ & $\mathbf{1 8 5 , 2 2 0}$ & $\mathbf{4 9 8 , 2 0 0}$ & $\mathbf{6 6 , 0 0 0}$ \\
\hline
\end{tabular}

Note: Figures may not add up exactly due to rounding

The cohabiting and other/lone population for 2001 has been derived from the 2001 Census.

The populations for 2007 have been derived from cohabitation estimates. 
Appendix B

Age-specific fertility rates

Table B1 Estimated fertility rates by partnership status, age group and year, England and Wales

\begin{tabular}{|c|c|c|c|}
\hline $\begin{array}{l}\text { Year, age group } \\
2007\end{array}$ & Married & Cohabiting & Other/Lone \\
\hline Under 20 & 456.3 & 330.5 & 18.6 \\
\hline $20-24$ & 286.5 & 144.0 & 28.7 \\
\hline $25-29$ & 219.3 & 108.8 & 28.4 \\
\hline $30-34$ & 164.5 & 114.4 & 24.1 \\
\hline $35-39$ & 68.3 & 89.1 & 15.6 \\
\hline 40 and over & 12.3 & 29.2 & 4.8 \\
\hline \multicolumn{4}{|l|}{2001 Census $^{1}$} \\
\hline Under 20 & 287.1 & 269.8 & 21.1 \\
\hline $20-24$ & 228.9 & 128.2 & 26.5 \\
\hline $25-29$ & 164.9 & 90.4 & 23.6 \\
\hline $30-34$ & 117.0 & 95.3 & 19.0 \\
\hline $35-39$ & 46.6 & 65.5 & 11.5 \\
\hline 40 and over & 8.6 & 19.8 & 3.6 \\
\hline \multicolumn{4}{|l|}{1992} \\
\hline Under 20 & 286.7 & 192.0 & 22.0 \\
\hline $20-24$ & 196.3 & 127.9 & 31.0 \\
\hline $25-29$ & 169.5 & 107.9 & 32.7 \\
\hline $30-34$ & 103.3 & 101.2 & 26.3 \\
\hline $35-39$ & 35.5 & 62.3 & 13.3 \\
\hline 40 and over & 5.7 & 16.6 & 2.9 \\
\hline
\end{tabular}

1 For the 2001 cohabitation and other/lone ASFRs, the population denominator used was derived from the 2001 Census. For the other years, cohabitation estimates were used.

Note: Age specific fertility rates are presented as live births per 1,000 women aged 16-44

Source: Birth statistics, FM1 series, population estimates by marital status, ONS and cohabitation estimates, Office for National Statistics 


\section{References}

1 Population estimates by marital status are available at: www.statistics.gov.uk/statbase/Product.asp?vlnk=15107

2 Marriage data for 2008 are provisional. See Table 5 Marriage statistics, 2008 (provisional) available at: www.statistics.gov.uk/statbase/Product.asp?vlnk=14275

3 Wilson, B (2009) 'Estimating the cohabiting population' Population Trends 136, 22. Available at: www.statistics.gov.uk/articles/population_trends/PT136EstimatingCohabitation.pdf The latest 2007 cohabitation estimates (as of March 2010) were used in the 2006-based marital status projections and are available at:

www.statistics.gov.uk/downloads/theme_population/MaritalStatusProjection06.pdf.

The 2008 cohabitation estimates used in the 2008-based marital status projections are available from June 2010.

4 Results from the General Lifestyle Survey (previously General Household Survey), Table 3.3. Available at: www.statistics.gov.uk/StatBase/Product.asp?vInk=5756\&Pos=2\&ColRank=2\&Rank=416

5 Chamberlain, J and Gill, B (2005) Chapter 5: Fertility and mortality, Focus on People and Migration 2005, Office for National Statistics, Palgrave.

6 Figures for 2002 to 2008 are based on population estimates for March 2010. These figures may change due to revised estimates published in May 2010.

7 Standardised mean age of mother, Table 1.7b, FM1 Birth Statistics. Available at: www.statistics.gov.uk/StatBase/Product.asp?vlnk=5768. See also reference 6 .

8 Table 3.2, Birth Statistics 1837-1983: Historic Series FM1, HMSO and Table 3.1 - Live births by age of mother. Available at: www.statistics.gov.uk/STATBASE/Product.asp?vlnk=15354

9 Smallwood, S (2002) 'The Effect of Changes in Timing of Childbearing on Measuring Fertility in England and Wales', Population Trends 109, 39.

10 In a few cases, a joint registration is made in the absence of the father if an affiliation order or statutory declaration is provided.

11 The Births and Deaths Registration Act 1953, which covers all aspects of the registration of births, and the Statistics and Registration Service Act 2007 and the Population (Statistics) Acts 1938 and 1960, which deal with the statistical information collected at registration.

12 Smallwood, S (2004) 'Characteristics of sole registered births and the mothers who register them', Population Trends 117, 21.

13 Table 1.1, Birth Statistics 1837-1983: Historic Series FM1, HMSO.

14 See reference 1.

15 Age-specific marital fertility rates for ages under 20 are likely to fluctuate due to the small number of women who marry at this age. For example, see Hinde, P R A (1998) Demographic Methods, Arnold.

16 For example, in 2008, 53 per cent of women having a birth within marriage aged under 20 , had their first birth within one year of marriage, compared with less than 20 per cent of all women 
having a first birth within marriage. See Table 5.1, FM1 Birth Statistics, 2008, Office for National Statistics. Available at: www.statistics.gov.uk/downloads/theme_population/FM1-37/FM1_37_2008.pdf

17 A factor has a positive impact on the proportion of births outside marriage when holding it constant at an earlier year's level results in a reduction in the proportion of births outside marriage compared with the proportion actually observed in the year of interest. Conversely, a factor has a negative impact if holding it constant at the earlier year's value results in an increase in the expected proportion compared with the observed.

18 Such babies may be born to two parents who are in a relationship but not cohabiting, or to parents who are not in a relationship but wish to have the father's details included on the birth certificate.

19 For example see reference 3 and Murphy, M (2000) 'The evolution of cohabitation in Britain, 1960-95', Population Studies 54: 1, 43-56.

20 See reference 1 for population estimates by marital status. For detail on the methodology behind marital status estimates, see: www.statistics.gov.uk/about/data/methodology/specific/ population/downloads/Marital_Status_Estimation_Methodology_Feb_2010.pdf. From 2002 onwards, population estimates by marital status include the estimated number of marriages that take place abroad each year to residents of England and Wales. Marital status estimates for 1991-2001 have not been explicitly adjusted to take account of marriages abroad; however they were rebased in light of the 2001 Census and this should have corrected for any discrepancy arising from an undercount of marriages abroad during the 1990s. Therefore, estimated marital and non-marital fertility rates for the 1990s and for the years since 2001 should be broadly comparable in terms of continuity in the denominators.

21 The cohabitation estimates have historically used the Labour Force Survey and General Household Survey, with the Annual Population Survey added to the methodology for 2007. For further information see reference 3.

22 The 1991-2008 time series used for the initial inside/outside marriage analysis is not available for the comparable cohabitation analysis. Estimated fertility rates are generally presented for three comparison years 1992, 2001 and 2007 with 1996 and 2003 added for extra detail.

23 See reference 3.

24 One particular issue in estimating fertility rates for cohabiting women is the treatment of the separated (but legally married). These women are counted as married in the marital status estimates, but are separately identified in the cohabitation estimates. In the latter, if they are living with a new partner (and not yet divorced) then they are identified as cohabiting (separated). Otherwise they are identified as separated (not cohabiting). In 2007, 2.3 per cent of women aged 16 to 44 were separated (but legally married), and this comprised 0.2 per cent who were cohabiting and 2.1 per cent who were not.

25 Table 3.b FM1 Birth statistics, 2008, Office for National Statistics. Available at: www.statistics.gov.uk/downloads/theme_population/FM1-37/FM1_37_2008.pdf

26 Whether or not the 'separated but legally married' population is included in the denominator for the cohabiting fertility rates has an effect on the results for 2007. Overall, the differences are small, and the inclusion of this population in the non-married categories (cohabiting and 
other/lone) results in their TFRs being 0.03 children per woman lower in 2007 . For the older age groups, where the probability of being already married and participating in is higher, the differences are larger, with some age-specific rates varying by up to 13 per cent (e.g. for the other/lone aged $40+$ ). The maximum percentage change in ASFRs for those cohabiting was also for those aged $40+$, and was less than 4 per cent.

27 Gray, J, Stockard, J and Stone, J (2006) 'The rising share of nonmarital births - fertility choice or marriage behaviour?' Demography 43 (2), 241-253.

28 Martin, S (2009) 'Comment: There may be compositional effects but they do not work that way', Demography 46 (1), 203-208.

29 This is not an issue for marital fertility rates of those aged under 20 , where the denominator corresponds to the population at risk (although there may be exceptional cases where young women may have married abroad aged under 16). However, it may artificially inflate non-marital fertility rates for under 20 s, as some of the population at risk will be under 16 (hence the denominator is artificially low). Marital and non-marital fertility rates in this article match published figures except for the under 20 age group. See Table 3.1b, FM1 Birth Statistics, 2008, Office for National Statistics. Available at:

www.statistics.gov.uk/StatBase/Product.asp?vlnk=5768

30 If all separated women were moved from the married population to the unmarried population denominator, then estimated marital fertility rates would become slightly higher and estimated non-marital fertility rates slightly lower (however, some separated women may register births within marriage if they were conceived with the former husband; therefore the best treatment of separated women in this respect is not clear cut).

31 See reference 3.

32 Fertility rates among cohabiting women aged under 20 are very high like those of married women under 20, which may result from a selection effect (see reference 15).

33 The differences in the ASFRs for married and cohabiting women aged 40 and over may not be significant due to the small number of births to women in this age group. However the significance has not been tested explicitly here.

34 Steele, F, Kallis, C, Goldstein, H and Joshi, H (2005) 'The relationship between childbearing and transitions from marriage and cohabitation in Britain'. Demography 42(4). And Steele, F, Joshi, H, Kallis, C and Goldstein, H (2006) 'Changing compatibility of cohabitation and childbearing between young British women born in 1958 and 1970'. Population Studies 60 (2).

35 Such births may be registered either within a civil partnership or outside a civil partnership where 'agreed female parenthood conditions apply'. Human Fertilisation and Embryology Act 2008 Available at: www.opsi.gov.uk/acts/acts2008/ukpga_20080022_en_6\#pt2

36 See DCSF White Paper (2008) - Joint birth registration: Recording responsibility. Available at: http://publications.dcsf.gov.uk/default.aspx?PageFunction=productdetails\&PageMode= publications\&Productld=CM\%25207293. The document sets out a series of non-legislative measures to promote and support joint birth registration and changes that give mothers a right to insist that the father acknowledges his responsibilities to his child by registering on the birth certificate. Equally, it gives a father a new right to insist that he is registered. Sole registrations will be permitted only where a specified exemption applies, for example where the father is 
unknown. The relevant amendments to the Births and Deaths Registration Act 1953 have been made as part of the Welfare Reform Act 2009. Available at: www.opsi.gov.uk/RevisedStatutes/ Acts/ukpga/2009/cukpga_20090024_en_16

37 See schedule 6 of the Welfare Reform Act 2009 for new wording of the Population (Statistics) Act 1938. Available at:

www.opsi.gov.uk/RevisedStatutes/Acts/ukpga/2009/cukpga_20090024_en_17.

Prior to these amendments, only married women were asked about previous children and whether they had previously been married. 